\title{
Carboxyl-terminated butadiene-acrylonitrile-toughened epoxy/carboxyl-modified carbon nanotube nanocomposites: Thermal and mechanical properties
}

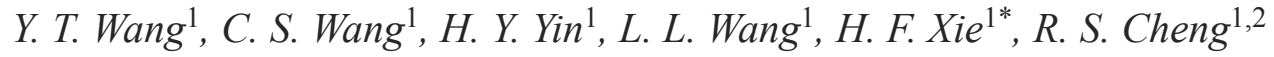 \\ ${ }^{1}$ Key Laboratory for Mesoscopic Chemistry of Ministry of Education, Department of Polymer Science and Engineering, \\ School of Chemistry and Chemical Engineering, Nanjing University, 210093 Nanjing, China \\ ${ }^{2}$ College of Material Science and Engineering, South China University of Technology, 510640 Guangzhou, China
}

Received 21 January 2012; accepted in revised form26 March 2012

\begin{abstract}
Carboxyl-modified multi-walled carbon nanotubes (MWCNT-COOHs) as nanofillers were incorporated into diglycidyl ether of bisphenol A (DGEBA) toughened with carboxyl-terminated butadiene-acrylonitrile (CTBN). The carboxyl functional carbon nanotubes were characterized by Fourier-transform infrared spectroscopy and thermogravimetric analysis. Furthermore, cure kinetics, glass transition temperature $\left(T_{\mathrm{g}}\right)$, mechanical properties, thermal stability and morphology of DGEBA/CTBN/MWCNT-COOHs nanocomposites were investigated by differential scanning calorimetry (DSC), dynamic mechanical analysis (DMA), universal test machine, thermogravimetric analysis and scanning electron microscopy (SEM). DSC kinetic studies showed that the addition of MWCNT-COOHs accelerated the curing reaction of the rubber-toughened epoxy resin. DMA results revealed that $T_{\mathrm{g}}$ of rubber-toughened epoxy nanocomposites lowered with MWCNT-COOH contents. The tensile strength, elongation at break, flexural strength and flexural modulus of DGEBA/ CTBN/MWCNT-COOHs nanocomposites were increased at lower MWCNT-COOH concentration. A homogenous dispersion of nanocomposites at lower MWCNT-COOH concentration was observed by SEM.
\end{abstract}

Keywords: nanocomposites, thermal properties, thermosetting resin, carbon nanotubes, epoxy resin

\section{Introduction}

Epoxy resins are widely used as coatings, adhesives, insulating materials and matrices for fibrous composites for their rigidity, high temperature performance, chemical resistance and adhesive properties. However, the inherent brittleness due to the high crosslinking density becomes one of the biggest troubles in advanced application use in industries. Therefore, great efforts have been exerted in the modifications of epoxy resins for further improvement of multifunctional properties $[1,2]$.

Presently, reactive liquid rubber, thermoplastics, interpenetrating polymer networks (IPNs), thermotropic liquid crystal and nanofillers are used to toughen epoxies for improving properties of epoxy networks. The elastomeric toughening is the most frequently used and widely accepted among these methods. Recently, Tripathi and Srivastava $[1,3]$ reported that a two-phase morphology was observed and the best balance of mechanical properties were achieved with a concentration of carboxyl-terminated butadiene-acrylonitrile (CTBN) ranging between 15 and $20 \mathrm{phr}$ (part per hundred resin) in the cured epoxy resin. Varley [4] effectively toughened the diglycidyl ether of bisphenol A (DGEBA) by both epoxy-terminated aliphatic polyesters and CTBN with a great improvement of the fracture properties whereas the addition of aminopropyl-ter-

\footnotetext{
${ }^{*}$ Corresponding author, e-mail:hfxie@nju.edu.cn
}

(C) BME-PT 
minated siloxane showed no improvement due to the poor dispersion. Kishi et al. [5] found that though the CTBN/DGEBA/DDM (diamino diphenyl methane) resins indicated high damping performance and high adhesive strength to aluminum substrates, there was always loss of strength of the materials accompanied with the improvement of toughness. The work of Ratna and Banthia [6] showed that the tensile strength and flexural strength of the epoxy resins modified by carboxyl terminated poly(2-ethylhexyl acrylate) decreased rapidly with increase of the rubber. Similar observations have been reported by other authors $[7,8]$.

Carbon nanotubes (CNTs) and carbon nanofibers (CNFs) are considered as reinforcement for polymer matrix because of the remarkable physical, chemical and electrical properties with small dimensions and high aspect ratios [9-12]. In order to transfer the outstanding properties to the modified epoxy, functionalization of pristine CNTs is essential for getting strong interfacial bonding and proper dispersion [13-17]. Gojny et al. [18] studied the mechanical properties of epoxy matrix composites with different types of CNTs which exhibited an improved strength, stiffness and fracture toughness. Liu and Wagner [19] reported two epoxy matrices with widely different mechanical properties both were reinforced by CNTs. Sui et al. [20] reported that epoxy resins were reinforced and toughened more effectively by CNTs than CNFs [21]. However, the enhancement was not as significant as expected. Recently, Hsieh et al. [22] proved that the addition of CNTs increased the modulus of the epoxy. The measured fracture energy was increased, from 133 to $223 \mathrm{~J} / \mathrm{m}^{2}$ with the addition of $0.5 \mathrm{wt} \%$ of nanotubes.

To our knowledge, few studies have been carried out on the influence of CNTs on the rubber-tough- ened epoxy [23]. In present paper, CTBN and carboxyl-functionalized multi-walled carbon nanotubes (MWCNTs) were first reacted with DGEBA to form adducts, which were then cured with a flexible curing agent, Jeffamine to further increase the toughness of the epoxy. The dynamic cure kinetics, thermal stability, glass transition temperature, mechanical properties, and morphology of carboxyl-functionalized MWCNT/epoxy/rubber nanocomposites were studied.

\section{Experimental \\ 2.1. Materials}

The epoxy resin used in this study was DGEBA, E51, with an epoxide equivalent weight of $196 \mathrm{~g} / \mathrm{eq}$, from Wuxi Resin Factory (Wuxi, China). The curing agent was Jeffamine, T403, from Huntsman Corporation (Texas, USA). The elastomeric toughener used was a liquid CTBN rubber with an acrylonitrile content of 30-35\%, from Lanzhou Petrochemical Company (Lanzhou, China). Chemical structures of DGEGBA, Jeffamine and CTBN are showed in Figure 1. MWCNTs with diameters of 40-60 $\mathrm{nm}$ and lengths of 5-15 $\mu \mathrm{m}$ were supplied by Shenzhen Nanotech Port Co. Ltd. (Shenzhen, China).

\subsection{Sample preparation}

3 g MWCNTs were mixed with $100 \mathrm{~mL}$ nitric acid with a concentration of $5 \mathrm{~mol} / \mathrm{L}$ and sonicated for $1 \mathrm{~h}$ in water bath, then the suspension reacted at $130^{\circ} \mathrm{C}$ for $10 \mathrm{~h}$. After they were washed with deionized water until the filtrate reached a $\mathrm{pH}$ value of $c a .6-7$, MWCNT-COOHs were dried in vacuum at $60^{\circ} \mathrm{C}$ for 3 day and collected then.

DGEBA and $15 \mathrm{phr}$ (part per hundred resin) CTBN were mixed, then MWCNT-COOHs were added, the mixture was reacted for $2 \mathrm{~h}$ with mechanical
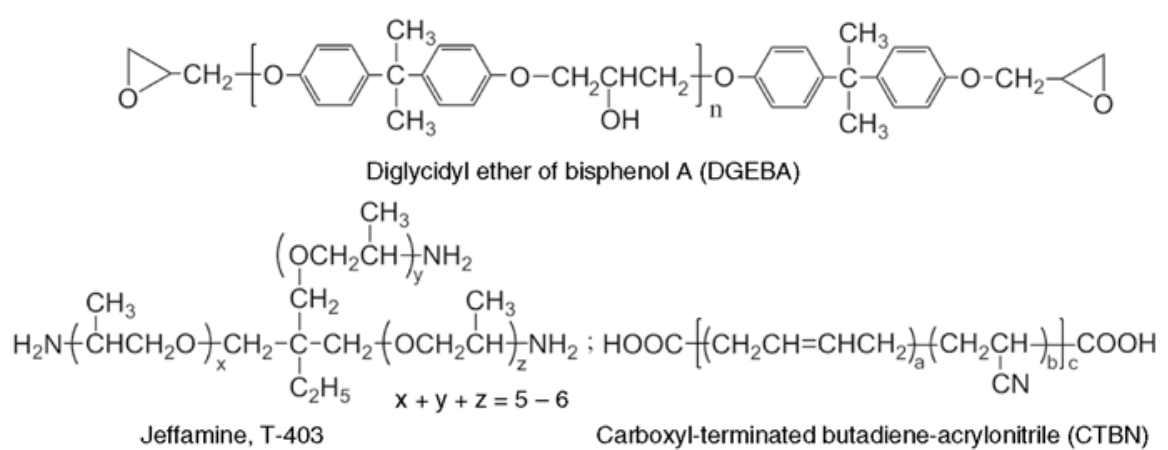

Figure 1. Chemical structures of DGEBA, Jeffamine and CTBN 


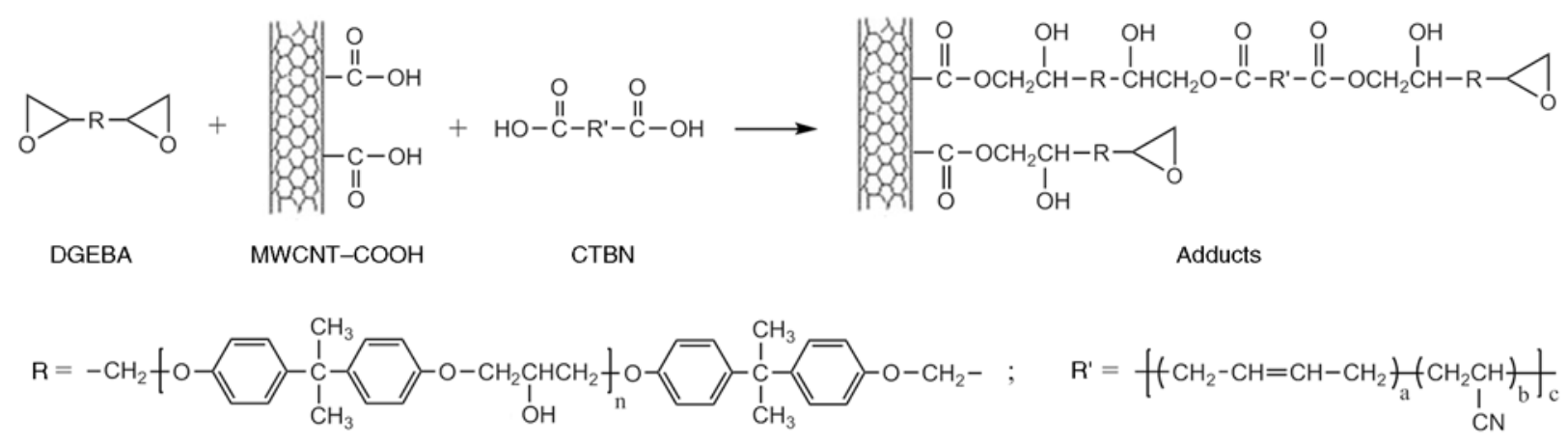

Figure 2. The reaction scheme between carboxyl groups in CTBN and MWCNT-COOHs and epoxy groups in DGEBA

stirring at $145^{\circ} \mathrm{C}$ and then sonicated for $1.5 \mathrm{~h}$ at $30^{\circ} \mathrm{C}$, during which adducts could be formed among DGEBA, CTBN and MWCNT-COOHs, as shown in Figure 2. The adducts were placed in an oil bath at $75^{\circ} \mathrm{C}$, then a stoichiometric amount of Jeffamine was added with continuous mechanical stirring until a homogeneous mixture was observed. Several DSC aluminum pans were filled with the reaction mixture. The mixtures $(c a .10 \mathrm{mg}$ ) were then cooled and stored in a freezer until they were required for the DSC measurements. Other mixtures were immediately poured into polytetrafluoroethylene molds and cured for $2 \mathrm{~h}$ at $80^{\circ} \mathrm{C}$ and $3 \mathrm{~h}$ at $125^{\circ} \mathrm{C}$. DGEBA/ CTBN/MWCNT-COOHs nanocomposites with 0 , $0.5,1,2 \mathrm{wt} \%$ MWCNT-COOHs noted as MWCNT 0 , MWCNT 0.5, MWCNT 1 and MWCNT 2, respectively.

\subsection{Characterization}

The FT-IR spectrum of MWCNT-COOHs was recorded on a Nicolet Avatar 360 FT-IR spectrometer (Thermo Scientific, USA) in the wavelength range of $4000-400 \mathrm{~cm}^{-1}$, at a resolution of $4 \mathrm{~cm}^{-1}$. MWCNT-COOHs were pressed into a pellet together with potassium bromide $(\mathrm{KBr})$ powder. Studies on dynamic curing kinetics of epoxy nanocomposites were performed on Pyris 1 DSC (Perkin-Elmer, USA) under an argon flow of $20 \mathrm{~mL} / \mathrm{min}$. The samples for kinetic analysis were heated up from 50 to $300^{\circ} \mathrm{C}$ at heating rates of $5,10,15$ and $20^{\circ} \mathrm{C} / \mathrm{min}$, respectively. The $T_{\mathrm{g}} \mathrm{s}$ of the cured samples were tested using dynamic mechanical analysis (DMA; $\mathrm{DMA}+450,01 \mathrm{~dB}-$ Metravib, France). The measurements were taken under tension mode from -80 to $140^{\circ} \mathrm{C}$ with a frequency of $1 \mathrm{~Hz}$ at a heating rate of $2^{\circ} \mathrm{C} / \mathrm{min}$. All mechanical tests were performed on an Instron 4466 universal material tester (Instron, USA) at room temperature. The tensile tests were measured according to ASTM D638 at $5 \mathrm{~mm} / \mathrm{min}$. For the flexural test, rectangular specimens were cut with dimensions of $100 \times 10 \times 5 \mathrm{~mm}$ according to ASTM-D790 and tested at a crosshead speed of $4 \mathrm{~mm} / \mathrm{min}$. Four specimens were tested in the mechanical measurements. TGA was performed at a Pyris 1 thermogravimetric analyzer (PerkinElmer, USA) with a heating rate of $20^{\circ} \mathrm{C} / \mathrm{min}$ over a temperature range of $25-600^{\circ} \mathrm{C}$ under a nitrogen flow of $40 \mathrm{~mL} / \mathrm{min}$. Scanning electronic microscopy (SEM) images of the fracture surfaces were obtained on a Hitachi S-4800 field-emission scanning electronic microscope (Hitachi, Japan). The cured samples were fractured under liquid nitrogen, and then the fractured surfaces were vacuum-coated with a thin gold layer.

\section{Results and discussion}

\subsection{Characterization of carboxyl-modified carbon nanotubes}

Figure 3 shows the FT-IR spectrum of MWCNTCOOHs. The peaks at around 3435 and $1714 \mathrm{~cm}^{-1}$ could be respectively assigned to the $\mathrm{O}-\mathrm{H}$ stretching vibrations and $\mathrm{C}=\mathrm{O}$ stretching vibrations, so it

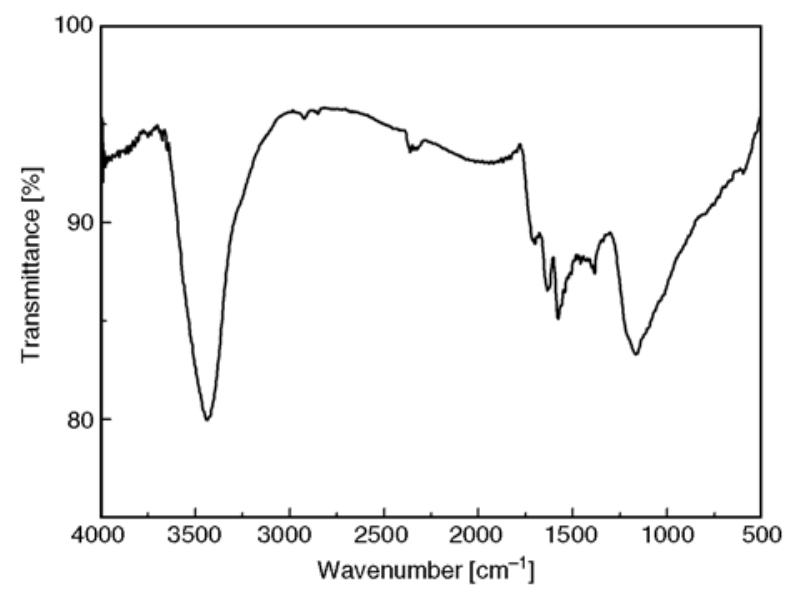

Figure 3. FT-IR spectrum of carboxyl-modified MWCNTs 


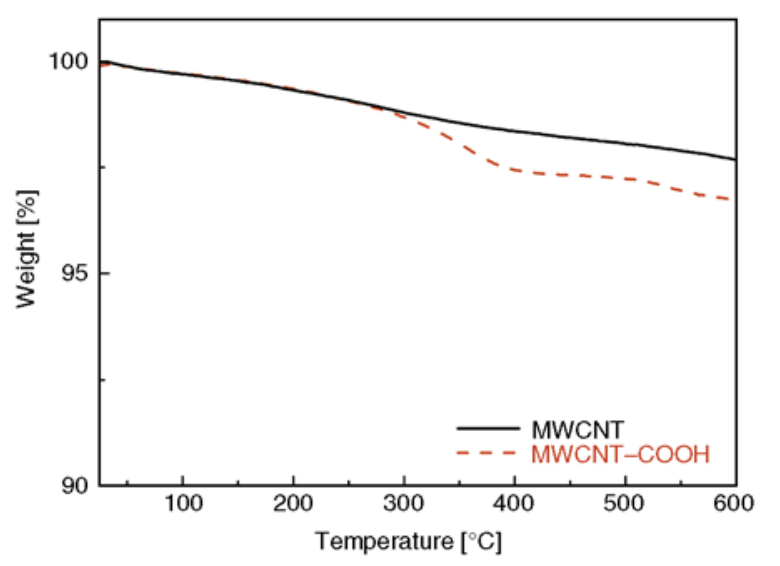

Figure 4. TGA curves of MWCNT and carboxyl-modified MWCNTs

is clear that MWCNTs were successfully modified with the introduction of the carboxyl functionalities. Besides, the peaks observed at around 1579 and $1384 \mathrm{~cm}^{-1}$ should be ascribed to the carbonic $\mathrm{C}-\mathrm{C}$ stretch bonds [24].

The samples of MWCNTs and MWCNT-COOHs were studied with TGA (as shown in Figure 4). Compared with the pristine MWCNTs, carboxylfunctionalized MWCNTs displayed more weight loss between 300 and $600^{\circ} \mathrm{C}$. This weight loss results from the losing of carboxyl groups on the surface of MWCNTs.

\subsection{Cure behaviors}

DSC is often used to study the effect of nanofillers on the cure behaviors of epoxy resin [11, 16, 25-27]. In present work, dynamic kinetic studies based on Kissinger and Flynn-Wall-Ozawa (FWO) models [26-28] were utilized to investigate the DGEBA/ CTBN/MWCNT-COOHs nanocomposites. Both

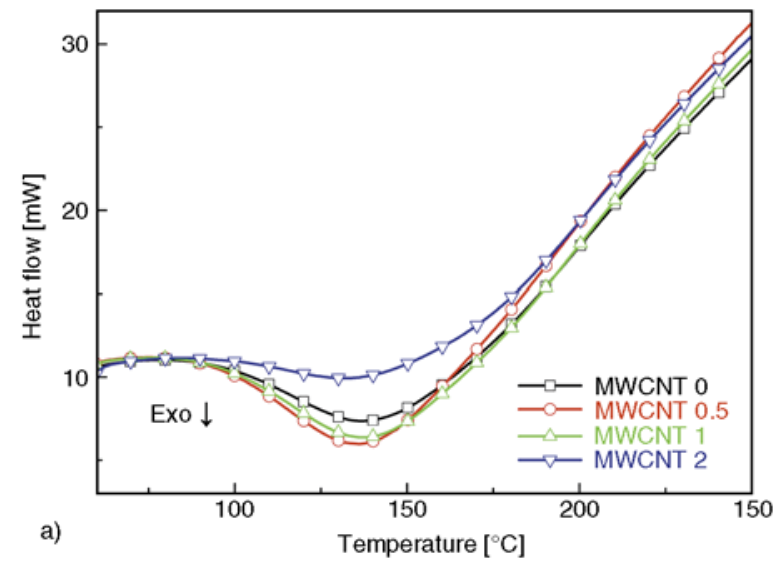

models do not require prior knowledge of the reaction mechanism.

According to the Kissinger model [28], the activation energy can be obtained from Equation (1):

$\frac{\mathrm{d}\left[\ln \left(\beta / T_{\mathrm{p}}^{2}\right)\right]}{\mathrm{d}\left(1 / T_{\mathrm{p}}\right)}=-\frac{E_{\alpha}}{R}$

where $T_{\mathrm{p}}$ is the peak exothermal temperature, $\beta$ is the constant heating rate, $E_{\alpha}$ is the activation energy of the reaction, and $R$ is the universal gas constant. The value of $E_{\alpha}$ can be obtained by plotting $\ln \left(T_{\mathrm{p}}^{2}\right)$ versus $1 / T_{\mathrm{p}}$.

The Flynn-Wall-Ozawa (FWO) model [29, 30] yields a simple relationship between the activation energy $E_{\alpha}$, the heating rate $\beta$, and the peak exothermal temperature $T_{\mathrm{p}}$, giving the activation energy as shown by Equation (2):

$$
\log \beta=A-0.457 \frac{E_{\alpha}}{R T_{\mathrm{p}}}
$$

Figure 5 shows DSC thermograms from dynamic heating experiments and conversion versus temperature curves for DGEBA/CTBN/MWCNT-COOHs nanocomposites conducted at a heating rate of $20^{\circ} \mathrm{C} / \mathrm{min}$, while the conversion is definited as the ratio of the heat generated up to time $t$ to the total heat of the reaction. Clearly, the samples with MWCNT$\mathrm{COOHs}$ reacted faster than the rubber-only toughened epoxy (MWCNT 0). Furthermore, the reaction rate of MWCNT-COOHs nanocomposites increased with the rise of MWCNT-COOH contents. The initial reaction temperature $\left(T_{\mathrm{i}}\right)$, exothermal peak temperature $\left(T_{\mathrm{p}}\right)$ and heat of curing $(\Delta H)$ of DGEBA/ CTBN/MWCNT-COOHs nanocomposites at differ-

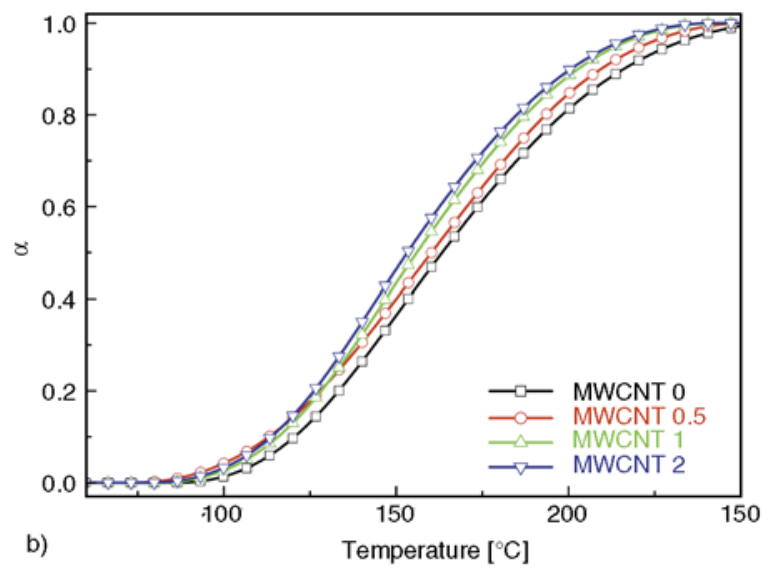

Figure 5. DSC curves (a) and relationship between conversion $(\alpha)$ and temperature $(b)$ for DGEBA/CTBN/MWCNT-COOHs nanocomposites at a heating rate of $20^{\circ} \mathrm{C} / \mathrm{min}$ 
ent heating rates are listed in Table 1. It is observed that both $T_{\mathrm{i}}$ and $T_{\mathrm{p}}$ decrease with the increase of MWCNT-COOH contents, indicating that MWCNT$\mathrm{COOH}$ act as catalysts and facilitate the curing reaction and the catalytic effect increases with the MWCNT-COOH contents.

By applying the Kissinger and FWO methods, activation energies can be obtained from the slope of

Table 1. The initial temperature, peak temperature and heat of curing for DGEBA/CTBN/MWCNT-COOHs nanocomposites

\begin{tabular}{|c|c|c|c|c|}
\hline $\begin{array}{c}\text { MWCNT-COOH } \\
\text { [wt\%] }\end{array}$ & $\begin{array}{c}\text { Heating rate } \\
{\left[{ }^{\circ} \mathrm{C} / \mathrm{min}\right]}\end{array}$ & $\begin{array}{c}\mathbf{T}_{\mathbf{i}} \\
{\left[{ }^{\circ} \mathbf{C}\right]}\end{array}$ & $\begin{array}{c}\mathbf{T}_{p} \\
{\left[{ }^{\circ} \mathbf{C}\right]}\end{array}$ & $\begin{array}{c}\Delta \mathbf{H} \\
{[\mathbf{J} / \mathbf{g}]}\end{array}$ \\
\hline \multirow{4}{*}{0} & 5 & 80.500 & 107.200 & 315.255 \\
\hline & 10 & 81.100 & 121.200 & 313.661 \\
\hline & 15 & 83.100 & 130.100 & 318.466 \\
\hline & 20 & 87.700 & 137.200 & 315.875 \\
\hline \multirow{4}{*}{0.5} & 5 & 78.600 & 103.300 & 313.303 \\
\hline & 10 & 79.300 & 120.800 & 306.760 \\
\hline & 15 & 81.200 & 127.300 & 313.697 \\
\hline & 20 & 85.100 & 135.100 & 310.983 \\
\hline \multirow{4}{*}{1} & 5 & 75.300 & 102.600 & 312.719 \\
\hline & 10 & 78.000 & 118.100 & 308.868 \\
\hline & 15 & 80.500 & 126.600 & 305.528 \\
\hline & 20 & 81.200 & 134.500 & 299.297 \\
\hline \multirow{4}{*}{2} & 5 & 73.400 & 100.000 & 310.877 \\
\hline & 10 & 76.700 & 116.000 & 296.764 \\
\hline & 15 & 78.600 & 125.300 & 291.877 \\
\hline & 20 & 79.900 & 132.500 & 284.224 \\
\hline
\end{tabular}

Table 2. Activation energies of DGEBA/CTBN/MWCNTCOOHs nanocomposites

\begin{tabular}{|c|c|c|}
\hline \multirow{2}{*}{$\begin{array}{c}\text { MWCNT-COOH } \\
{[\mathbf{w t} \% \mathbf{0}}\end{array}$} & \multicolumn{2}{|c|}{$\mathbf{E}_{\boldsymbol{\alpha}}[\mathbf{k J} / \mathbf{m o l}]$} \\
\cline { 2 - 3 } & Kissinger & FWO \\
\hline 0 & 53.6 & 57.2 \\
\hline 0.5 & 49.7 & 53.4 \\
\hline 1 & 49.4 & 53.1 \\
\hline 2 & 47.3 & 51.1 \\
\hline
\end{tabular}

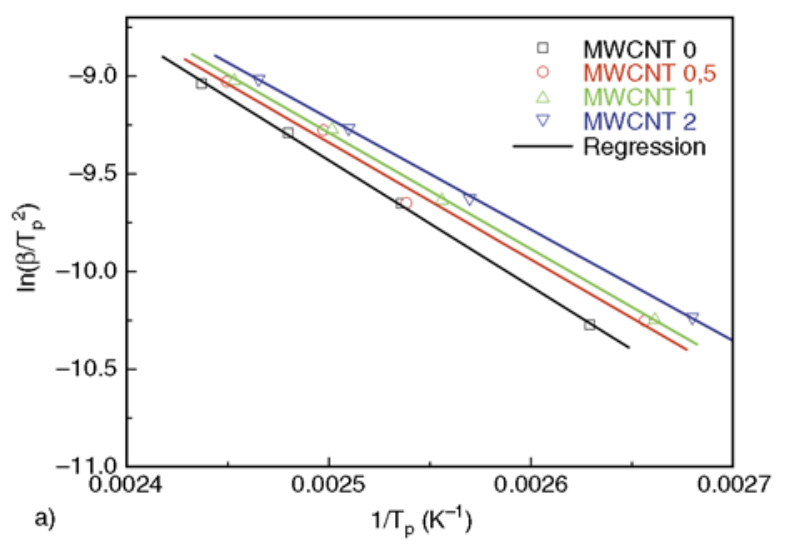

the lines as presented in Figure 6. Linear relationships were obtained, confirming the validity of the models for the systems under study. Table 2 summarizes the results obtained from the dynamic kinetic analysis. The activation energies calculated from the two models were in close agreement. It is obvious that $E_{\alpha}$ of nanocomposites decreased with the increasing of MWCNT-COOH contents. A decrease in activation energy implies that less energy of the reacting resin components is required and indicates an accelerating effect. This suggests that the addition of carboxyl-MWCNTs into rubbertoughened epoxy resin facilitates the curing reaction, which is consistent with the results of other workers $[31,32]$. The high thermal conductivity of the MWCNTs is considered to be the origin for the decrease in activation energy [31].

\subsection{Glass transition temperature $\left(T_{\mathrm{g}}\right)$}

The loss tangent $(\tan \delta)$ as a function of temperature is shown in Figure 7. The temperature at which the $\tan \delta$ is maximum is defined as $T_{\mathrm{g}}$. The $T_{\mathrm{g}}$ of MWCNT 0.5 was almost equal to that of MWCNT0, but it decreased markedly with the increasing of MWCNT-COOH contents. One possibility is that the addition of MWCNT-COOHs causes over-stoichimetric active hydrogen which can react with the epoxy groups, since it is well known that the stoichimetric ratio of curing agent to epoxide group leads to maximum $T_{\mathrm{g}}$ [33]. Similar results were reported in fluorinated MWCNTs/epoxy nanocomposites [34]. The introduction of MWCNT-COOHs would increase the viscosity of the mixture significantly, resulting in the rapid decrease of the cure degree in the diffusion-controlled stage. Thus, $T_{\mathrm{g}} \mathrm{s}$ of the MWCNT-COOHs nanocomposites are expected

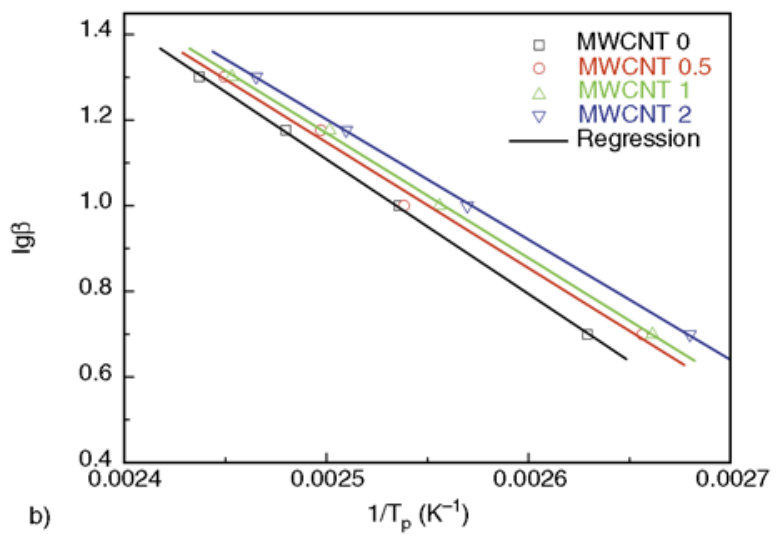

Figure 6. Relationship between $\ln \left(\beta / T_{\mathrm{p}}^{2}\right)$ and $1 / T_{\mathrm{p}}$ (a) and between $\ln \beta(\mathrm{b})$ and $1 / T_{\mathrm{p}}$ (b) for DGEBA/CTBN/MWCNT-COOHs nanocomposites 


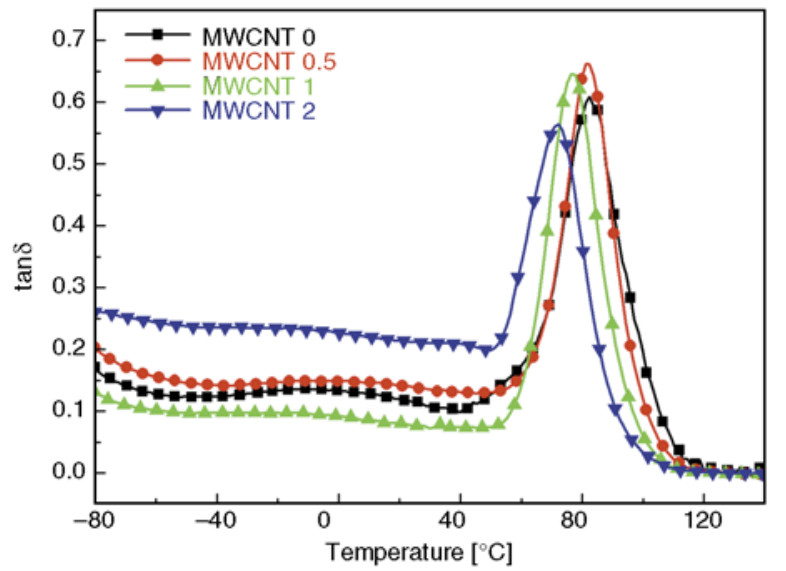

Figure 7. Temperature dependence of $\tan \delta$ for the CTBNtoughed epoxy and DGEBA/CTBN/MWCNTCOOHs nanocomposites

to be lower than the rubber-only toughened one (MWCNT 0). Though MWCNTs could limit the mobility of the polymer chains to elevate the $T_{\mathrm{g}} \mathrm{s}$ of the composites, the effect was counterbalanced by the poor dispersion of MWCNT-COOHs for MWCNT 1 and MWCNT2 [26].

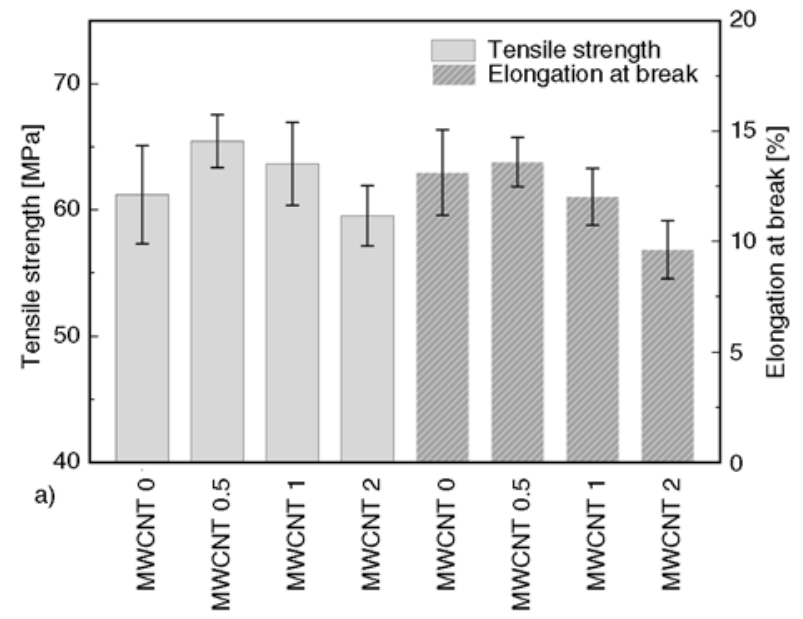

\subsection{Mechanical properties}

To evaluate the effects of MWCNT-COOHs on the mechanical properties of the toughened epoxy, tensile tests and flexural tests were performed, as showed in Figure 8a and 8b, respectively. It is known that the addition of rubber inevitably decreases the tensile strength of epoxy resin. With the addition of MWCNT-COOHs, tensile strengths of MWCNT 0.5 and MWCNT 1 and elongation at break of MWCNT 0.5 were greater than that of rubber-toughened epoxy (MWCNT0). Moreover, with the increasing of MWCNT-COOH content, the tensile strength and elongation at break decreased gradually. As shown in Figure $8 b$, with the incorporation of CTBN, the addition of MWCNT-COOHs increased the flexural strength modulus of rubber-toughened epoxy. Furthermore, the flexural strength and modulus for DGEBA/CTBN/MWCNT-COOHs nanocomposites decreased with the increasing of MWCNT-COOH contents. The mechanical properties of nanocomposites depend on the dispersion of

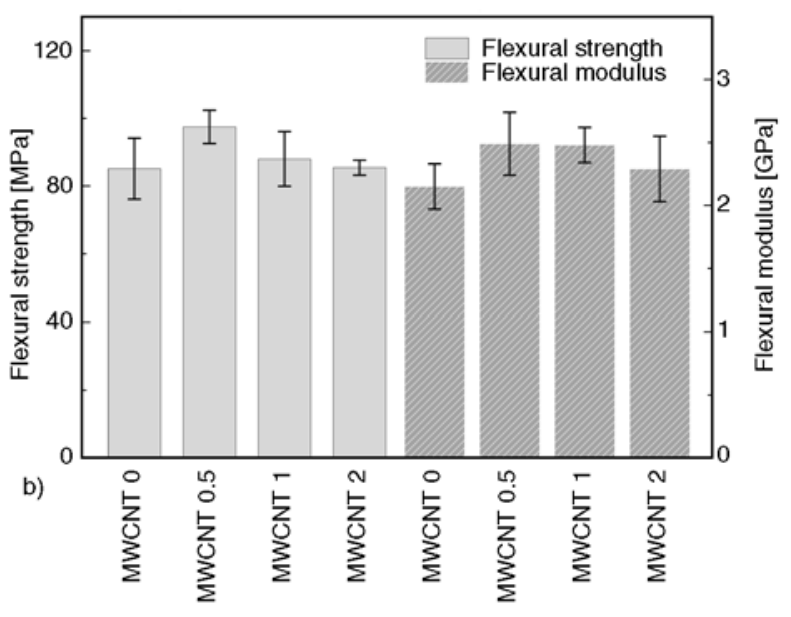

Figure 8. Tensile strengths and elongations at break (a) and flexural strengths and flexural moduli (b) for the CTBNtoughed epoxy and DGEBA/CTBN/MWCNT-COOHs nanocomposites
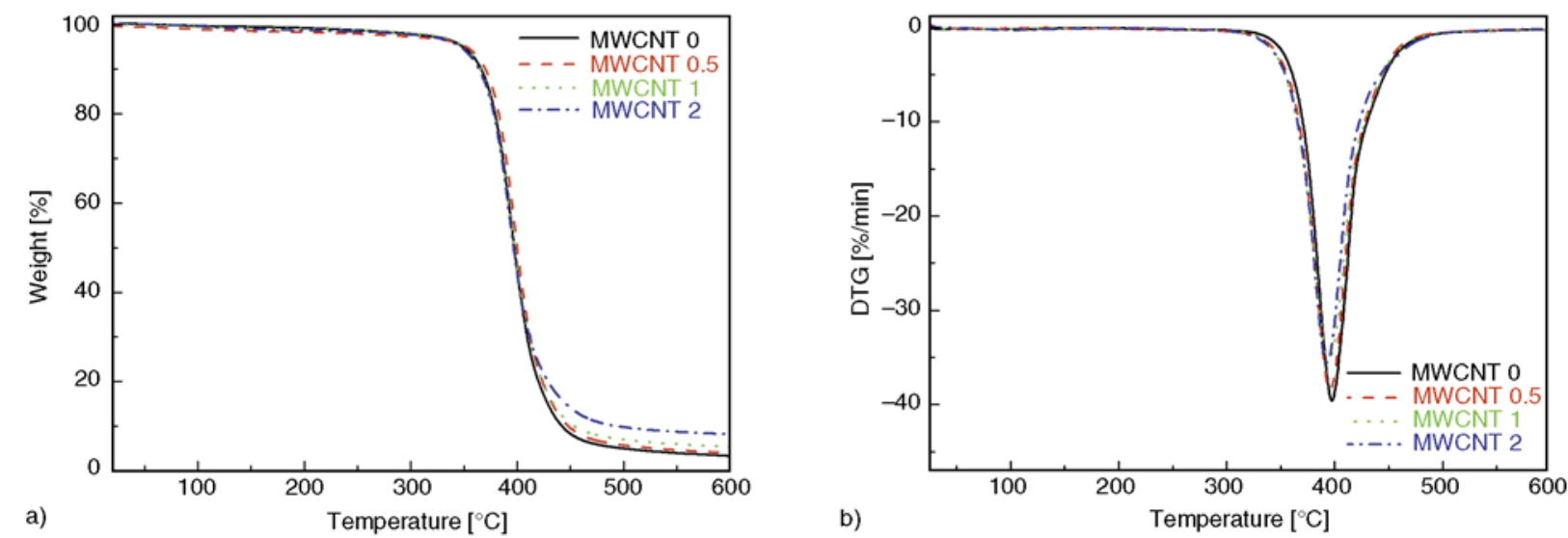

Figure 9. TGA (a) and DTG (b) curves for DGEBA/CTBN/MWCNT-COOHs nanocomposites 
carbon nanotubes in the polymer matrix and the interaction between nanotubes and polymers [35, 36]. In other words, more homogeneous dispersion and better interface between the nanotubes and the epoxy matrix result in better mechanical properties. For MWCNT-COOHs, good dispersion can be achieved at lower concentration. However, higher nanotube concentration will cause higher viscosity

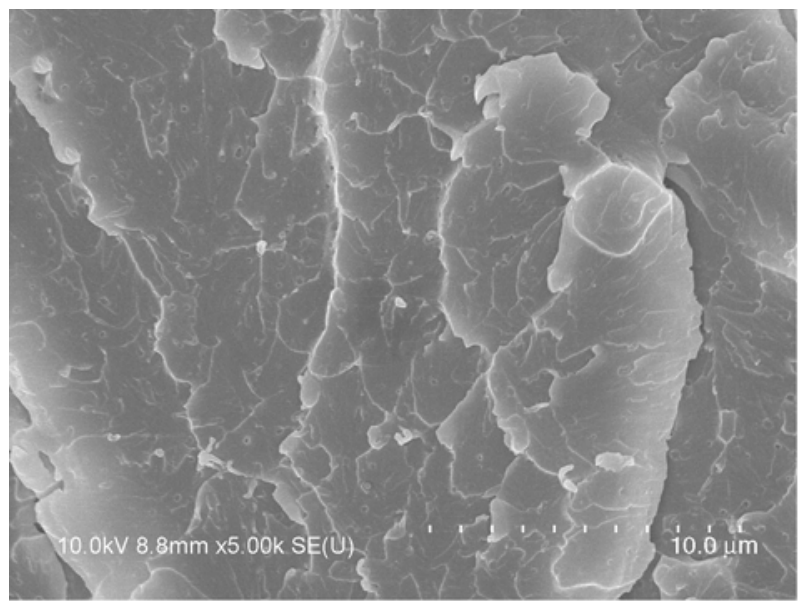

a)

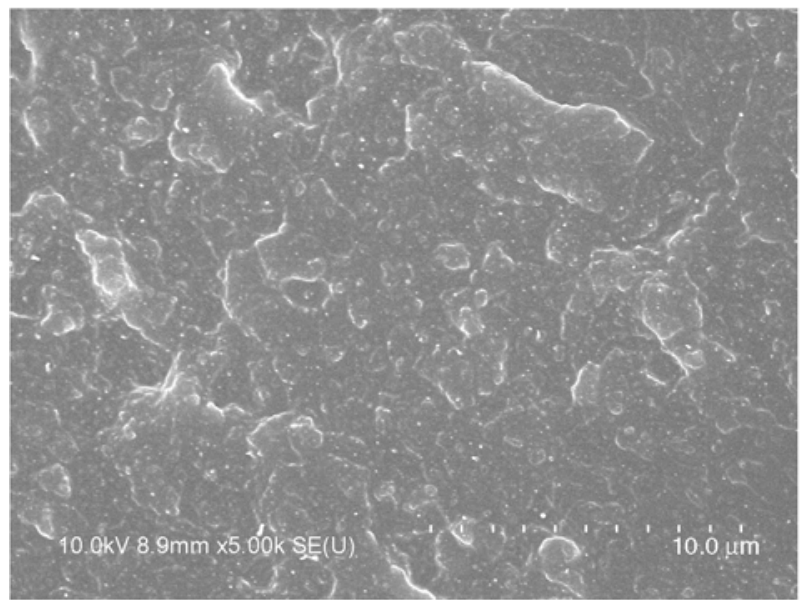

c)
Table 3. TGA and DTG results for DGEBA/CTBN/ MWCNT-COOH nanocomposites

\begin{tabular}{|c|c|c|c|}
\hline $\begin{array}{c}\text { MWCNT } \\
{[\mathbf{w t} \% \mathbf{~}]}\end{array}$ & $\begin{array}{c}\text { IDT } \\
{\left[{ }^{\circ} \mathbf{C}\right]}\end{array}$ & $\begin{array}{c}\mathbf{T}_{\max } \\
{\left[{ }^{\mathbf{}} \mathbf{C}\right]}\end{array}$ & $\begin{array}{c}\text { Residue at } \mathbf{6 0 0}^{\circ} \mathbf{C} \\
{[\mathbf{\%}]}\end{array}$ \\
\hline 0 & 349 & 397 & 3.2 \\
\hline 0.5 & 352 & 395 & 3.9 \\
\hline 1 & 350 & 395 & 5.3 \\
\hline 2 & 347 & 393 & 8.2 \\
\hline
\end{tabular}

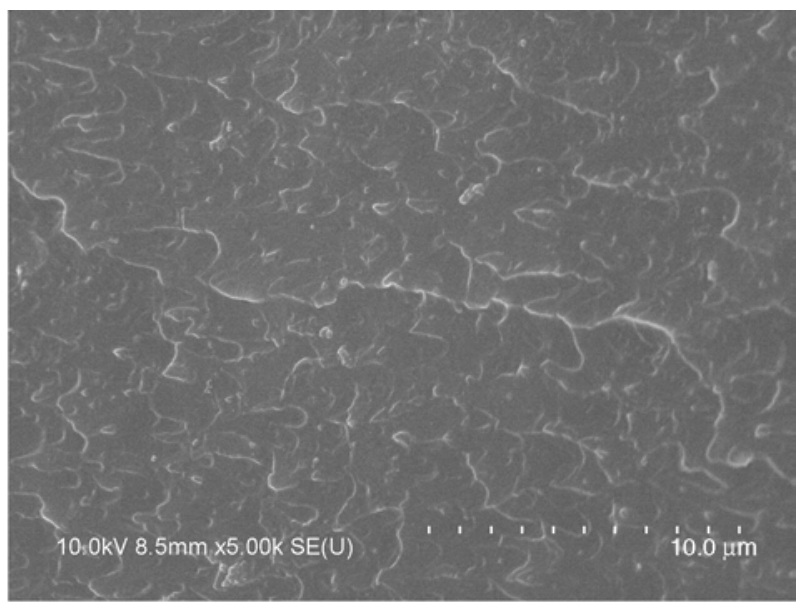

b)

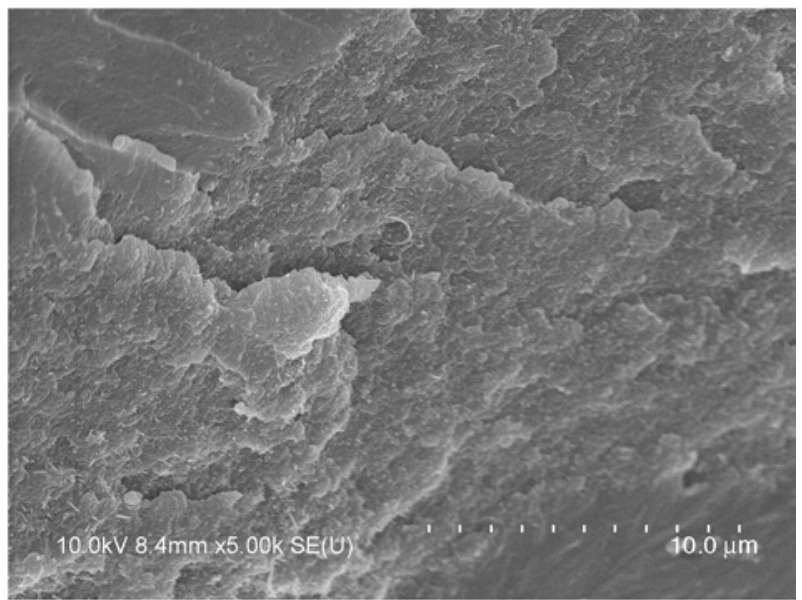

d)

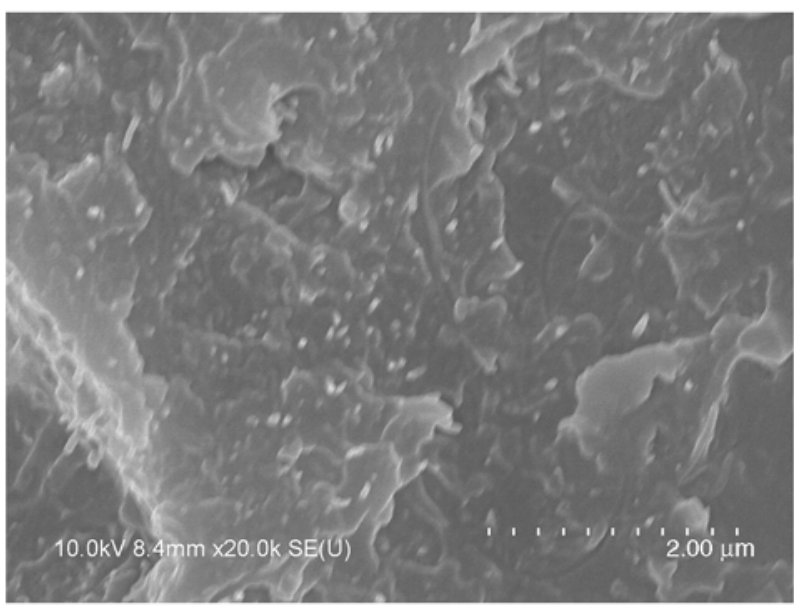

e)

Figure 10. SEM images of cryo-fracture surfaces for (a) MWCNT 0, (b) MWCNT 0.5, (c) MWCNT 1 and (d) MWCNT 2; (e) high magnification image of (d) 
and agglomerates with poor dispersion. The agglomerates present in poorly dispersed nanocomposites cause cracks to initiate and propagate easily. The generated cracks reduce the strength of the rubbertoughed epoxy nanocomposites.

\subsection{Thermal stability}

TGA and DTG curves for DGEBA/CTBN nanocomposites with different concentration of MWCNTCOOHs are presented in Figure 9. The initial decomposition temperature (IDT) which is set as the temperature at $5 \%$ weight loss, maximum rate of degradation temperatures $\left(T_{\max }\right)$ and residue at $600^{\circ} \mathrm{C}$ are summarized in Table 3 . The negligible changes of IDTs and $T_{\max }$ s illustrate that MWCNTCOOHs do not affect the thermal stabilities of the resin matrices. The residues of the nanocomposites at $600^{\circ} \mathrm{C}$ increased with the growing concentration of MWCNT-COOHs. In Figure 9b, every curve showed a single peak at about $396^{\circ} \mathrm{C}$, proving the strong interaction of the epoxy with CTBN and MWCNT-COOHs.

\subsection{Morphology}

SEM images of cryo-fracture surfaces for rubbertoughened epoxy and its MWCNT-COOHs nanocomposites are shown in Figure 10. Two-phase morphology was easily observed in MWCNT0 (Figure 10a). MWCNT-COOHs dispersed relatively uniformly at a low concentration in the CTBNtoughened epoxy system (MWCNT 0.5, Figure 10b), while agglomerates were increased in both size and amount with the increasing of the concentration of MWCNT-COOHs, as shown in Figure 10c and 10d. These results indicate the existence of strong interfacial bonding between $0.5 \mathrm{wt} \%$ MWCNTCOOHs and CTBN-toughened epoxy in the nanocomposites. In contrast, $2 \mathrm{wt} \% \mathrm{MWCNT}-\mathrm{COOHs}$ have weak interfacial interactions with the rubber toughened matrix because of the agglomeration of MWCNT-COOHs. Many MWCNT-COOHs were pulled out from the fractured surface (Figure 10e), which phenomena have also been observed in our previous reports [17]. The poor dispersion of MWCNTs had significant influence on the glass transition temperature and mechanical properties of nanocomposites as discussed above.

\section{Conclusions}

Carboxyl-modified multi-walled carbon nanotubes were successfully prepared by treating MWCNTs with acid and then incorporated into the epoxy/ CTBN matrix. Dynamic kinetic analysis showed that the activation energy of rubber-toughened epoxy nanocomposites decreased with the increasing of MWCNT-COOH contents, indicating carboxyl-functionalized carbon nanotubes accelerate the cure reactions of the rubber-toughened epoxy system. The incorporation of MWCNT-COOHs improved mechanical properties of the CTBN-toughened epoxy systems, whereas the improvement was not linear with the concentration of MWCNT$\mathrm{COOHs}$. The maximum tensile and flexural properties were obtained at MWCNT-COOH concentration of $0.5 \mathrm{wt} \%$ with uniform dispersion. Nevertheless, at higher concentrations, MWCNT-COOHs agglomerated in the viscous epoxy/CTBN system and resulted in the decreasing of mechanical properties. The glass transition temperature of rubbertoughened nanocomposites decreased with the increasing MWCNT-COOH contents.

\section{Acknowledgements}

The authors would like to thank the Fundamental Research Funds for the Central Universities (1106020514) for financial support.

\section{References}

[1] Tripathi G., Srivastava D.: Studies on the physicomechanical and thermal characteristics of blends of DGEBA epoxy, 3,4 epoxy cyclohexylmethyl, 3',4'epoxycylohexane carboxylate and carboxyl terminated butadiene co-acrylonitrile (CTBN). Materials Science and Engineering: A, 496, 483-493 (2008).

DOI: $10.1016 /$ j.msea.2008.06.035

[2] Thomas R., Ding Y., He Y., Yang L., Moldenaers P., Yang W., Czigany T., Thomas S.: Miscibility, morphology, thermal, and mechanical properties of a DGEBA based epoxy resin toughened with a liquid rubber. Polymer, 49, 278-294 (2008).

DOI: $10.1016 /$ j.polymer.2007.11.030

[3] Tripathi G., Srivastava D.: Effect of carboxyl-terminated poly(butadiene-co-acrylonitrile) (CTBN) concentration on thermal and mechanical properties of binary blends of diglycidyl ether of bisphenol-A (DGEBA) epoxy resin. Materials Science and Engineering: A, 443, 262-269 (2007).

DOI: $10.1016 /$ j.msea.2006.09.031 
[4] Varley R. J.: Toughening of epoxy resin systems using low-viscosity additives. Polymer International, 53, 78-84 (2004).

DOI: $10.1002 /$ pi.1321

[5] Kishi H., Nagao A., Kobayashi Y., Matsuda S., Asami T., Murakami A.: Carboxyl-terminated butadiene acrylonitrile rubber/epoxy polymer alloys as damping adhesives and energy absorbable resins. Journal of Applied Polymer Science, 105, 1817-1824 (2007). DOI: 10.1002/app.26189

[6] Ratna D., Banthia A. K.: Toughened epoxy adhesive modified with acrylate based liquid rubber. Polymer International, 49, 281-287 (2000).

DOI: $10.1002 /(\mathrm{SICI}) 1097-0126(200003) 49: 3<281:$ : AID-PI353>3.0.CO;2-F

[7] Day R. J., Lovell P. A., Wazzan A. A.: Thermal and mechanical characterization of epoxy resins toughened using preformed particles. Polymer International, 50, 849-857 (2001).

DOI: $10.1002 /$ pi.690

[8] Du J., Thouless M. D., Yee A. F.: Development of a process zone in rubber-modified epoxy polymers. International Journal of Fracture, 92, 271-285 (1998). DOI: 10.1023/A:1007530801531

[9] Bokobza L.: Multiwall carbon nanotube elastomeric composites: A review. Polymer, 48, 4907-4920 (2007). DOI: $10.1016 /$ j.polymer.2007.06.046

[10] Byrne M. T., Gun'ko Y. K.: Recent advances in research on carbon nanotube-polymer composites. Advanced Materials, 22, 1672-1688 (2010). DOI: $10.1002 /$ adma.200901545

[11] Xie H., Liu B., Sun Q., Yuan Z., Shen J., Cheng R.: Cure kinetic study of carbon nanofibers/epoxy composites by isothermal DSC. Journal of Applied Polymer Science, 96, 329-335 (2005).

DOI: $10.1002 / a p p .21415$

[12] Xie H., Liu B., Yang H., Wang Z., Shen J., Cheng R.: Thermal characterization of carbon-nanofiber-reinforced tetraglycidyl-4,4'-diaminodiphenylmethane/ 4,4'-diaminodiphenylsulfone epoxy composites. Journal of Applied Polymer Science, 100, 295-298 (2006). DOI: $10.1002 /$ app.23106

[13] Ma P. C., Kim J-K., Tang B. Z.: Effects of silane functionalization on the properties of carbon nanotube/ epoxy nanocomposites. Composites Science and Technology, 67, 2965-2972 (2007).

DOI: $10.1016 /$ j.compscitech.2007.05.006

[14] Wang S., Liang Z., Liu T., Wang B., Zhang C.: Effective amino-functionalization of carbon nanotubes for reinforcing epoxy polymer composites. Nanotechnology, 17, 1551-1557 (2006).

DOI: $10.1088 / 0957-4484 / 17 / 6 / 003$

[15] Xie H., Liu C., Yuan Z., Yang H., Wang Z. L., Cheng R.: Thermoanalytical studies of high performance epoxy/carbon nanotube composites. Acta Polymerica Sinica, 4, 332-336 (2008).

DOI: $10.3724 /$ SP.J.1105.2008.00332
[16] Xie H., Liu B., Yuan Z., Shen J., Cheng R.: Cure kinetics of carbon nanotube/tetrafunctional epoxy nanocomposites by isothermal differential scanning calorimetry. Journal of Polymer Science Part B: Polymer Physics, 42, 3701-3712 (2004).

DOI: $10.1002 /$ polb.20220

[17] Wang C., Chen X., Xie H., Cheng R.: Effects of carbon nanotube diameter and functionality on the properties of soy polyol-based polyurethane. Composites Part A: Applied Science and Manufacturing, 42, 16201626 (2011).

DOI: 10.1016/j.compositesa.2011.07.010

[18] Gojny F. H., Wichmann M. H. G., Fiedler B., Schulte $\mathrm{K}$.: Influence of different carbon nanotubes on the mechanical properties of epoxy matrix composites $-\mathrm{A}$ comparative study. Composites Science and Technology, 65, 2300-2313 (2005).

DOI: $10.1016 /$ j.compscitech.2005.04.021

[19] Liu L., Wagner H. D.: Rubbery and glassy epoxy resins reinforced with carbon nanotubes. Composites Science and Technology, 65, 1861-1868 (2005).

DOI: 10.1016/j.compscitech.2005.04.002

[20] Sui G., Zhong W. H., Liu M. C., Wu P. H.: Enhancing mechanical properties of an epoxy resin using 'liquid nano-reinforcements'. Materials Science and Engineering: A, 512, 139-142 (2009).

DOI: $10.1016 /$ j.msea.2009.01.023

[21] Sun L., Warren G., O’Reilly J. Y., Everett W. N., Lee S. M., Davis D., Lagoudas D., Sue H-J.: Mechanical properties of surface-functionalized SWCNT/epoxy composites. Carbon, 46, 320-328 (2008).

DOI: 10.1016/j.carbon.2007.11.051

[22] Hsieh T. H., Kinloch A. J., Taylor A. C., Kinloch I. A.: The effect of carbon nanotubes on the fracture toughness and fatigue performance of a thermosetting epoxy polymer. Journal of Materials Science, 46, 7525-7535 (2011).

DOI: $10.1007 / \mathrm{s} 10853-011-5724-0$

[23] Salinas-Ruiz M. d. M., Skordos A. A., Partridge I. K.: Rubber-toughened epoxy loaded with carbon nanotubes: structure-property relationships. Journal of Materials Science, 45, 2633-2639 (2010).

DOI: $10.1007 / \mathrm{s} 10853-010-4241-\mathrm{x}$

[24] Kim Y. J., Shin T. S., Choi H. D., Kwon J. H., Chung Y-C., Yoon H. G.: Electrical conductivity of chemically modified multiwalled carbon nanotube/epoxy composites. Carbon, 43, 23-30 (2005).

DOI: $10.1016 /$ j.carbon.2004.08.015

[25] Qiu S. L., Wang C. S., Wang Y. T., Liu C. G., Chen X. Y., Xie H. F., Huang Y. A., Cheng R. S.: Effects of graphene oxides on the cure behaviors of a tetrafunctional epoxy resin. Express Polymer Letters, 5, 809818 (2011).

DOI: $10.3144 /$ expresspolymlett.2011.79 
[26] Allaoui A., El Bounia N.: How carbon nanotubes affect the cure kinetics and glass transition temperature of their epoxy composites? - A review. Express Polymer Letters, 3, 588-594 (2009).

DOI: $10.3144 /$ expresspolymlett.2009.73

[27] Zhou T., Wang X., Liu X. H., Lai J. Z.: Effect of silane treatment of carboxylic-functionalized multi-walled carbon nanotubes on the thermal properties of epoxy nanocomposites. Express Polymer Letters, 4, 217-226 (2010).

DOI: $10.3144 /$ expresspolymlett.2010.28

[28] Kissinger H. E.: Reaction kinetics in differential thermal analysis. Analytical Chemistry, 29, 1702-1706 (1957).

DOI: $10.1021 / \mathrm{ac} 60131 \mathrm{a} 045$

[29] Flynn J. H., Wall L. A.: A quick, direct method for the determination of activation energy from thermogravimetric data. Journal of Polymer Scicence Part B: Polymer Letters, 4, 323-328 (1966).

DOI: $10.1002 /$ pol.1966.110040504

[30] Ozawa T.: Kinetic analysis of derivative curves in thermal analysis. Journal of Thermal Analysis, 2, 301324 (1970).

DOI: $10.1007 / \mathrm{BF} 01911411$

[31] Chen S., Hsu S-H., Wu M-C., Su W. F.: Kinetics studies on the accelerated curing of liquid crystalline epoxy resin/multiwalled carbon nanotube nanocomposites. Journal of Polymer Science Part B: Polymer Physics, 49, 301-309 (2011).

DOI: $10.1002 /$ polb.22179
[32] Choi W. S., Shanmugharaj A. M., Ryu S. H.: Study on the effect of phenol anchored multiwall carbon nanotube on the curing kinetics of epoxy/Novolac resins. Thermochimica Acta, 506, 77-81 (2010).

DOI: $10.1016 /$ j.tca.2010.04.019

[33] Gupta V. B., Drzal L. T., Lee C. Y-C., Rich M. J.: The temperature-dependence of some mechanical properties of a cured epoxy resin system. Polymer Engineering and Science, 25, 812-823 (1985).

DOI: $10.1002 /$ pen.760251305

[34] Miyagawa H., Rich M. J., Drzal L. T.: Thermo-physical properties of epoxy nanocomposites reinforced by carbon nanotubes and vapor grown carbon fibers. Thermochimica Acta, 442, 67-73 (2006). DOI: $10.1016 /$ j.tca.2006.01.016

[35] Tasis D., Tagmatarchis N., Bianco A., Prato M.: Chemistry of carbon nanotubes. Chemical Review, 106, 1105-1136 (2006). DOI: $10.1021 / \mathrm{cr} 0505690$

[36] Song Y. S., Youn J. R.: Influence of dispersion states of carbon nanotubes on physical properties of epoxy nanocomposites. Carbon, 43, 1378-1385 (2005). DOI: $\underline{10.1016 / \mathrm{j} . \text { carbon.2005.01.007 }}$ 